\title{
Correlation between fecal calprotectin, ulcerative colitis endoscopic index of severity and clinical outcome in patients with acute severe colitis
}

\author{
RONG MA ${ }^{1}$, RUI MENG ${ }^{2}$, XIANG ZHANG ${ }^{3}$, ZHIJUAN SUN $^{4}$ and YUANYUAN LEI ${ }^{2}$ \\ ${ }^{1}$ Department of Clinical Laboratory, Jining No. 1 People's Hospital, Jining, Shandong 272011; \\ ${ }^{2}$ Department of Gastroenterology, Dezhou People's Hospital, Dezhou, Shandong 253000; \\ ${ }^{3}$ Department of Clinical Laboratory, Qingdao Municipal Hospital, Qingdao, Shandong 266011; \\ ${ }^{4}$ Department of Clinical Laboratory, Qingdao No. 9 People's Hospital, Qingdao, Shandong 266005, P.R. China
}

Received September 3, 2019; Accepted December 3, 2019

DOI: $10.3892 /$ etm.2020.8861

\begin{abstract}
Correlation between fecal calprotectin (FC) and endoscopic activity assessed by Ulcerative Colitis Endoscopic Index of Severity (UCEIS) in acute severe colitis (ASC) patients was explored to evaluate the predictive value of $\mathrm{FC}$ in clinical outcomes. Seventy-one ASC patients were retrospectively evaluated. FC level within 3 days of colonoscopy was measured with ELISA. Demographic and clinical data, laboratory parameters, and medical therapy were documented, and the endoscopic severity of disease was rated by UCEIS. The end points were the rate of failed corticosteroid therapy, colectomy, and mortality. There was significant correlation between UCEIS and FC level $(\mathrm{r}=0.729, \mathrm{P}<0.001)$, which was superior to CRP, ESR, and hemoglobin. FC level between endoscopic mild activity (UCEIS, 3-4) and endoscopic moderate activity (UCEIS, 5-6), and endoscopic moderate activity (UCEIS, 5-6) and endoscopic severe activity (UCEIS, 7-8) were significantly different. FC levels were associated with different outcomes (failed corticosteroid therapy or surgery); when FC $>1672 \mu \mathrm{g} / \mathrm{g}$, sensitivity and specificity were 80.2 and $66.7 \%$, respectively, in prediction for colectomy using receiver operating characteristics analysis. The results indicated that FC, as a non-invasive indicator, correlates positively with the UCEIS. Baseline FC level predicts clinical outcomes in ASC patients, which make a timely treatment strategy conversion possible after accurately forecasting the likelihood of failure of intravenous steroid therapy.
\end{abstract}

Correspondence to: Dr Yuanyuan Lei, Department of Gastroenterology, Dezhou People's Hospital, 1166 Dongfanghong West Road, Dezhou, Shandong 253000, P.R. China

E-mail: 15615188209@163.com; lelv4e@163.com

Key words: fecal calprotectin, acute severe colitis, UCEIS, colectomy

\section{Introduction}

Approximately one-fifth of patients with ulcerative colitis (UC) develop acute severe ulcerative colitis (ASC) during disease progression $(1,2)$. In patients with ASC, intravenous glucocorticoids remain the basic treatment. When corticosteroid cannot control the disease, the treatment strategy should be adjusted in time to salvage treatment or surgical treatment (3). Delay in treatment increases the risk of treatment and surgical complications in ASC patients, and increases the financial burden of patients (4).

The determination of disease activity is an important basis for the evaluation of glucocorticoids or the adjustment of treatment regimens (5). Common methods for determining disease activity include clinical manifestations (body temperature, heart rate, times of stool blood), inflammatory indicators [C-reactive protein (CRP), erythrocyte sedimentation rate (ESR)], and endoscopic evaluation (6-8). At present, colonoscopy and, if necessary, colonoscopy specimen is still the gold standard for UC activity determination, and UC endoscopic severity score (UCEIS), as an objective and effective reflection and assessment of endoscopic intestinal mucosal injury, has largely reduced the subjective factors of clinicians (9-11). However, colonoscopy at ASC has the risk of causing intestinal perforation and aggravating toxic enteritis, and repeated colonoscopy increases patient suffering and risk when evaluating treatment outcomes (12). Therefore, it is necessary to implement a non-invasive, safe and accurate surrogate index reflecting the severity of the lesion under the endoscope.

Fecal calprotectin (FC) is derived from neutrophils and macrophages and is released into the feces along with degranulation of inflammatory cells during intestinal mucosal inflammation. It is stable in nature and can be stored at room temperature for 7 days without being decomposed by various bacteria and enzymes. It has a significant correlation with the degree of mucosal lesions and the therapeutic effect of the disease, and is a sensitive marker for the evaluation of inflammatory activity and therapeutic effects (13-15). As a non-invasive method, FC has some advantages that are not available in 
colonoscopy and hematologic inflammation indicators. However, in ASC patients, there are few related studies regarding the correlation between FC level and endoscopic intestinal mucosal inflammatory activity index and clinical outcomes. This study was designed to determine the association between FC and UCEIS and ASC clinical outcomes by measuring FC in patients with ASC of different endoscopy severity.

\section{Patients and methods}

Case selection. A retrospective analysis of UC patients who met our ASC criteria from January 2014 to April 2016 was performed. The diagnosis of UC is based on clinical signs and symptoms, laboratory tests, and pathology; the diagnosis of ASC is based on the Truelove-Witts criteria (16), which is bloody purulent stool $>6$ times/days, accompanied by any one or more of the following: heart rate $>90$ beats $/ \mathrm{min}$, body temperature $>37.8^{\circ} \mathrm{C}$, hemoglobin $(\mathrm{Hb})<10.5 \mathrm{~g} / \mathrm{dl}$, CRP $>30 \mathrm{mg} / \mathrm{dl}$ or ESR $>30 \mathrm{~mm} / \mathrm{h}$. All the patients underwent rectal sigmoidoscopy within one week of venous corticosteroid therapy and FC examination within 3 days of colonoscopy. All patients required a CT scan of the abdomen. The exclusion criteria were: age $<18$ years; ASC diagnosis was not clear; treatment data was incomplete, such as no colonoscopy, no FC results; venous corticosteroid or biological agents were used within 3 months. The study was approved by the Ethics Committee of Jining No. 1 People's Hospital (Jining, China). Signed informed consents were obtained from the patients and/or guardians.

UCEIS. The UCEIS scoring system consists of 3 parts, and the cumulative score is the final evaluation, including: vascular network (score 0-2), bleeding (score 0-3), erosion and ulceration (score 0-3), total score was $0-8$ points (Table I). Two endoscopists independently performed UCEIS assessments based on colonoscopy images, and the entire assessment process followed the blinded principle. When the two results were inconsistent, a senior doctor participated in the final judgment. According to the UCEIS cumulative score, the disease activity was divided into three levels: mild (UCEIS=2-4); moderate (UCEIS=5-6) and severe (UCEIS=7-8).

Collection and inspection of stool specimens. Stool samples (5-10 g) were collected within 3 days of colonoscopy for FC testing. The sample and the extractant were mixed according to weight: Volume $(\mathrm{g} / \mathrm{ml})=1: 49$ and thoroughly stirred. After centrifugation at high speed $\left(10,000 \times \mathrm{g}\right.$ at $4^{\circ} \mathrm{C}$ for $\left.5 \mathrm{~min}\right)$, the supernatant was collected for detection of $\mathrm{FC}$, and $1 \mathrm{ml}$ was reserved for use. Double antibody sandwich enzyme-linked immunosorbent assay (ELISA) was used to analyze the FC level, and the microplate reader detection wavelength was $450 \mathrm{~nm}$. If calprotectin was not detected at a ratio of 1:49, the dilution ratio was increased until detected.

Treatment strategy and clinical outcome evaluation. The patient's treatment process and related clinical decision-making after admission were based on the consensus opinion on the diagnosis and treatment of inflammatory bowel disease in China (17), and the patient's lesion range was based on Montréal classification (E1/E2/E3).
Patients with ASC were routinely given methylprednisolone $60 \mathrm{mg} /$ day or hydrocortisone $400 \mathrm{mg}$ /day after admission. The corticosteroid treatment effect was judged after 3-5 days of continuous administration. For patients with ineffective or partially effective outcomes, prolonged treatment time or salvage therapy (infliximab or cyclosporine) was given. The rescue treatment was intravenous infliximab $(0,2,6$ weeks; dose, $5 \mathrm{mg} / \mathrm{kg}$ ). For patients with persistent signs and symptoms, surgery was performed immediately after surgical indications such as gastrointestinal bleeding, intestinal perforation, or toxic megacolon. Patients with severe malnutrition were given enteral or parenteral nutritional support depending on their intestinal condition. For patients with hypoproteinemia [albumin (ALB) $<25 \mathrm{~g} / \mathrm{l}$ ], intravenous infusion of ALB was given. Low molecular weight heparin was routinely administered subcutaneously to prevent thrombosis.

Main outcome indicators include: i) Ineffective treatment of glucocorticoid, which indicates that after 3-5 days of continuous treatment of glucocorticoid, the symptoms did not improve significantly, and ultimately need to receive salvage treatment or even surgical treatment. ii) Surgery. After glucocorticoid or salvage treatment, some patients had continued deterioration of their symptoms, presenting surgical indications and eventually requiring surgery. Follow-up time: The median follow-up time was 14 days from the admission of the patient for acute severe ulcerative colitis to the discharge at the end of treatment.

Statistical methods. The data was statistically analyzed using SPSS 20.0 statistical software. A single sample Kolmogorov-Smirnov (K-S) test was used to test whether the data was normally distributed, and the median and quartile distance of FC were calculated. Mann-Whitney U test was used for comparison between non-normal distribution data sets; other measurement data were expressed as mean \pm standard deviation (mean $\pm \mathrm{SD}$ ), and t-test was performed. Correlation tests were performed using Spearman's rank correlation, and correlation coefficients were calculated. Sample size estimation was performed using MEDCAL 19.0 statistical software was used to calculate the sample size. The specific parameters were set as follows: Type I error $(\alpha$, significance $)=0.05$; type II error $(\beta, 1$-Power $)=0.10$; area under receiver operating characteristics $(\mathrm{ROC})$ curve $=0.75$; null hypothesis value $=0.5$; ratio of sample sizes in negative/positive groups $=2$. After calculation, the minimum sample size is $n=60$. The ROC curve was also plotted, and the area under the curve (AUC) was calculated for analysis. The Youden's index was used to calculate the diagnostic value, and the sensitivity and specificity of the diagnostic value were calculated. $\mathrm{P}<0.05$ was considered statistically significant.

\section{Results}

Patient data. In total, 71 patients with ASC were enrolled, and 32 patients achieved remission within 5 days of intravenous steroid therapy. Of the remaining 39 patients, 16 had surgery due to worsening symptoms. Eleven patients were treated with prolonged venous corticosteroid treatment (7-10 days), and the symptoms improved. Twelve patients were given salvage therapy; 8 patients were induced to 
Table I. Definition and composition of ulcerative colitis endoscopic severity score (UCEIS).

\begin{tabular}{|c|c|c|}
\hline $\begin{array}{l}\text { Parameters (the most severe } \\
\text { part of the lesion) }\end{array}$ & Score & Description \\
\hline \multirow[t]{3}{*}{ Vascular network } & Normal (0) & $\begin{array}{l}\text { Normal vascular network, clear branches of capillaries, } \\
\text { or blurred or partially missing edges of capillary networks. }\end{array}$ \\
\hline & Incomplete occlusion (1) & The vascular network is incompletely occluded. \\
\hline & Complete occlusion (2) & The vascular network is completely occluded. \\
\hline \multirow[t]{4}{*}{ Bleeding } & None $(0)$ & No visible bleeding. \\
\hline & Mucosal bleeding (1) & $\begin{array}{l}\text { The mucosal surface has coagulated bleeding spots } \\
\text { that can be washed away. }\end{array}$ \\
\hline & Mild bleeding in the lumen (2) & A small amount of active bleeding was seen in the lumen. \\
\hline & $\begin{array}{l}\text { Intracavitary moderate to } \\
\text { severe bleeding (3) }\end{array}$ & $\begin{array}{l}\text { Obvious bleeding observed in the lumen, or mucosal } \\
\text { oozing seen after flushing the lumen, or the mucosa } \\
\text { of active bleeding was observed. }\end{array}$ \\
\hline \multirow[t]{4}{*}{ Erosion and ulcer } & None $(0)$ & Normal mucosa, no erosion or ulceration. \\
\hline & Erosion (1) & $\begin{array}{l}\text { Small ( } \leq 5 \mathrm{~mm} \text { ) damaged mucosa with neat edge, } \\
\text { white or yellow. }\end{array}$ \\
\hline & Superficial ulcer (2) & $\begin{array}{l}\text { The larger ( }>5 \mathrm{~mm}) \text { mucosa is damaged, showing } \\
\text { discontinuous fibrin-covered ulcers, but still superficial. }\end{array}$ \\
\hline & Deep ulcer (3) & $\begin{array}{l}\text { The deep, transparent mucosa is damaged and the edges } \\
\text { are slightly raised. }\end{array}$ \\
\hline
\end{tabular}

Table II. Patient data.

\begin{tabular}{lc}
\hline Variable & mean $\pm \mathrm{SD}, \mathrm{n}(\%)$ \\
\hline Sex (\% female) & $39(54.9)$ \\
Age (years) & $42.1 \pm 14.8$ \\
Comorbidity & $18(17.8)$ \\
Course of disease (month) & $46.9 \pm 64.1$ \\
History of smoking (within one year) & $12(16.9)$ \\
Lesion and extent E2/E3 & $25(35.2) / 46(64.8)$ \\
Body temperature $\left({ }^{\circ} \mathrm{C}\right)$ & $37.0 \pm 0.6$ \\
Heart rate $(/$ min) & $82.5 \pm 13.3$ \\
Defecation frequency $(/ \mathrm{day})$ & $8.8 \pm 4.1$ \\
White blood cells $\left(\mathrm{x} 10^{7} / \mathrm{mm}^{3}\right)$ & $9.6 \pm 6.6$ \\
CRP $(\mathrm{mg} / \mathrm{l})$ & $37.3 \pm 28.6$ \\
ESR (mm/h) & $31.9 \pm 20.4$ \\
Hemoglobin $(\mathrm{g} / \mathrm{dl})$ & $101.3 \pm 22.7$ \\
\hline
\end{tabular}

E2, left colitis; E3, pancolitis; CRP, C-reactive protein.

remission, and 4 patients were treated with surgery after ineffective treatment. A total of 28 patients failed venous corticosteroid therapy, and 20 patients underwent surgical treatment during admission. General information of patients is shown in Table II.

Differences in FC and hematological parameters between different UCEIS score groups. FC was statistically different between UCEIS mild [2-4] and moderate [5-6] $(\mathrm{P}<0.001)$ and moderate and severe [7-8] $(\mathrm{P}=0.016)$. There was a significant difference in CRP, $\mathrm{Hb}$ and ALB between UCEIS mild and moderate groups $(\mathrm{P}=0.023, \mathrm{P}=0.011$ and $\mathrm{P}=0.016$, respectively), but there was no difference between moderate and severe groups $(\mathrm{P}=0.418, \mathrm{P}=0.211$ and $\mathrm{P}=0.071$, respectively). There was no difference in ESR between different groups $(\mathrm{P}=0.228$ and $\mathrm{P}=0.401)$ (Table III).

Correlation between UCEIS and FC and CRP, ESR and Hb. UCEIS was significantly associated with FC level $(r=0.7290$, $\mathrm{P}<0.001)$, significantly associated with CRP level $(\mathrm{r}=0.4889$, $\mathrm{P}<0.001)$, and had no significant correlation with ESR $(\mathrm{r}=0.0405, \mathrm{P}=0.736)$ and $\mathrm{Hb}(\mathrm{r}=-0.1965, \mathrm{P}=0.100)$ (Fig. 1).

FC and clinical outcome in patients with ASC

Diagnostic performance of FC on the failure rate of corticosteroid therapy in patients with ASC. When FC concentration was $>1327 \mu \mathrm{g} / \mathrm{g}$, UCEIS $>5.5$ and the concentration of ALB $<29.6 \mathrm{~g}$, Youdon's index was the highest, which was the best threshold for diagnosing venous corticosteroid induction failure. Correlation specificity, sensitivity, AUC and its $95 \%$ confidence interval are shown in Table IV. The ROC curve is shown in Fig. 2.

Diagnostic performance of FC in patients with ASC. According to the diagnostic efficacy of different cut-off points of FC and UCEIS scores in ASC patients, it was found that when the concentration of FC was $>1681 \mu \mathrm{g} / \mathrm{g}$, UCEIS $>6.5$ and the concentration of ALB $<25.8 \mathrm{~g}$, Youdon's index was the highest, which was the best threshold value for predicting the need for surgery in patients with ASC. The correlation specificity, sensitivity, AUC and its $95 \%$ confidence interval are shown in Table IV. The ROC curve is shown in Fig. 3. 
Table III. Fecal calprotectin, C-reactive protein, erythrocyte sedimentation rate and hemoglobin.

\begin{tabular}{lcccc}
\hline & $\begin{array}{c}\text { Mild (2-4) } \\
(34)\end{array}$ & $\begin{array}{c}\text { Moderate }(5-6) \\
(47)\end{array}$ & $\begin{array}{c}\text { Severe (7-8) } \\
(20)\end{array}$ & P1 \\
\hline FC $(\mu \mathrm{g} / \mathrm{g})$ & $690.5(57.7-1827.5)$ & $1393.1(603.5-2800.0)$ & $1872.6(900.3-2933.7)$ & $<0.001$ \\
CRP $(\mathrm{mg} / \mathrm{l})$ & $29.1 \pm 26.8$ & $40.2 \pm 26.1$ & $47.1 \pm 35.4$ & 0.016 \\
ESR $(\mathrm{mm} / \mathrm{h})$ & $29.1 \pm 19.7$ & $34.9 \pm 21.2$ & $29.7 \pm 20.1$ & 0.023 \\
Hb $(\mathrm{g} / \mathrm{l})$ & $111.0 \pm 22.4$ & $97.7 \pm 21.8$ & $89.9 \pm 18.2$ & 0.228 \\
ALB $(\mathrm{g} / \mathrm{l})$ & $39.6 \pm 11.7$ & $31.5 \pm 13.7$ & $28.2 \pm 9.9$ & 0.011 \\
\end{tabular}

P1, mild endoscopic activity (UCEIS, 2-4) vs moderate endoscopic activity (UCEIS, 5-6); P2, moderate endoscopic activity (UCEIS, 5-6) vs severe endoscopy activity (UCEIS, 7-8); FC, fecal calprotectin; CRP, C-reactive protein; ESR, erythrocyte sedimentation rate; Hb, hemoglobin; ALB, albumin.

Table IV. Diagnostic efficacy of different cut-off points of UCEIS and fecal calprotectin on clinical outcomes of ASC.

\begin{tabular}{lcccccr}
\hline Clinical outcome & Indicator & Sensitivity (\%) & Specificity (\%) & AUC & AUC 95\% CI & P-value \\
\hline Ineffective hormone therapy & UCEIS $>5.5$ & 65.8 & 85.2 & 0.847 & $0.768-0.926$ & $<0.001$ \\
& FC $>1327 \mu \mathrm{g} / \mathrm{g}$ & 60.5 & 76.4 & 0.805 & $0.692-0.875$ & $<0.001$ \\
& ALB $<29.6 \mathrm{~g} / \mathrm{l}$ & 60.1 & 73.4 & 0.747 & $0.616-0.792$ & 0.017 \\
Surgery & UCEIS $>6.5$ & 69.0 & 79.4 & 0.831 & $0.733-0.927$ & 0.010 \\
& FC $>1672 \mu \mathrm{g} / \mathrm{g}$ & 80.2 & 66.7 & 0.740 & $0.638-0.845$ & 0.006 \\
& ALB $<25.8 \mathrm{~g} / 1$ & 77.1 & 70.4 & 0.692 & $0.603-0.747$ & 0.036 \\
\hline
\end{tabular}

UCEIS, Ulcerative Colitis Endoscopic Index of Severity; ASC, acute severe colitis; FC, fecal calprotectin; ALB, albumin; AUC, area under the curve.
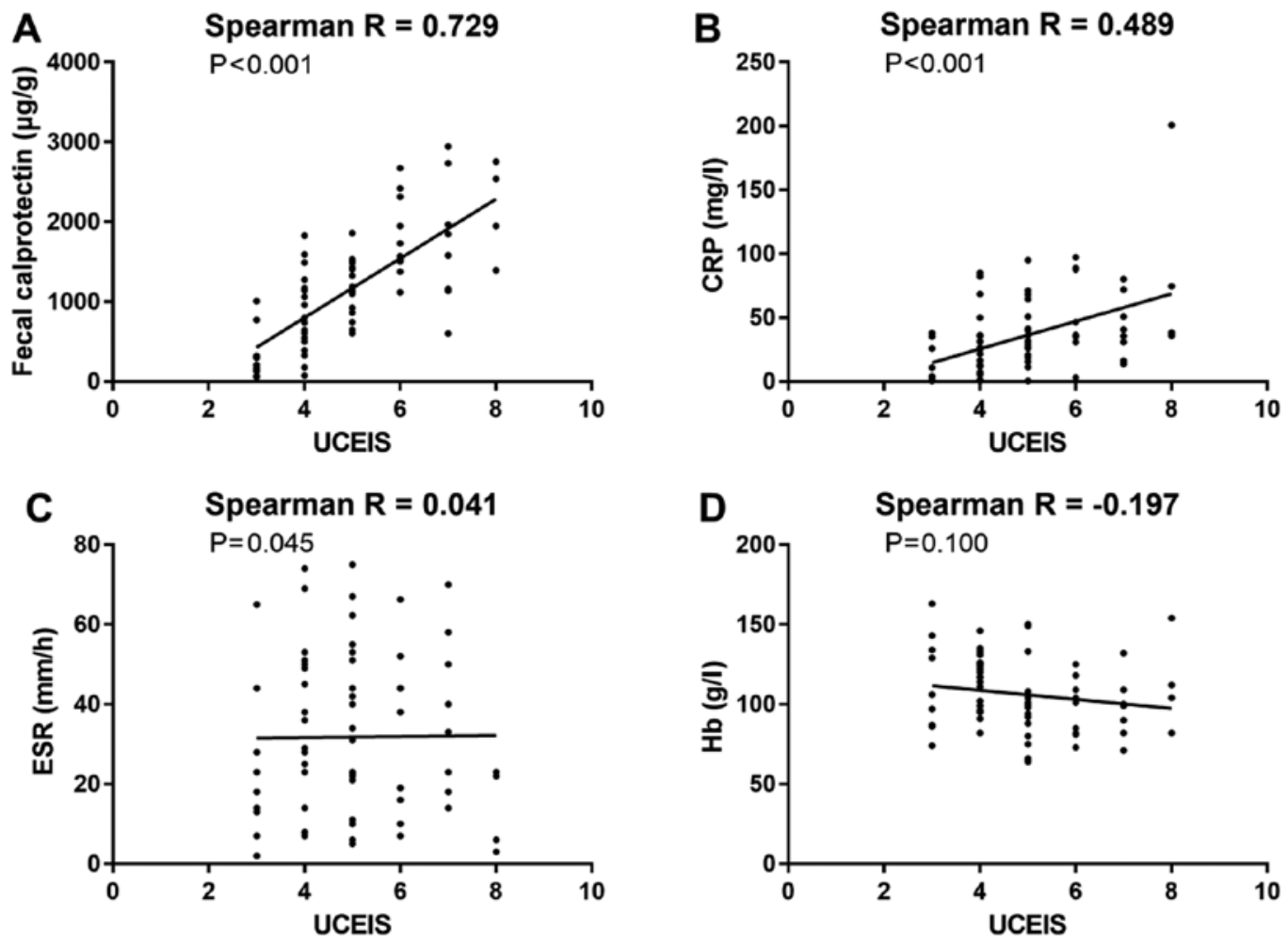

Figure 1. Correlation between UCEIS and fecal calprotectin and CRP, ESR and Hb. (A) Correlation between fecal calprotectin and UCEIS. (B) Correlation between CRP and ulcerative colitis endoscopic index of severity. (C) Correlation between ESR and ulcerative colitis endoscopic index of severity. (D) Correlation between $\mathrm{Hb}$ and ulcerative colitis endoscopic index of severity. UCEIS, Ulcerative Colitis Endoscopic Index of Severity; CRP, C-reactive protein; ESR, erythrocyte sedimentation rate; $\mathrm{Hb}$, hemoglobin. 


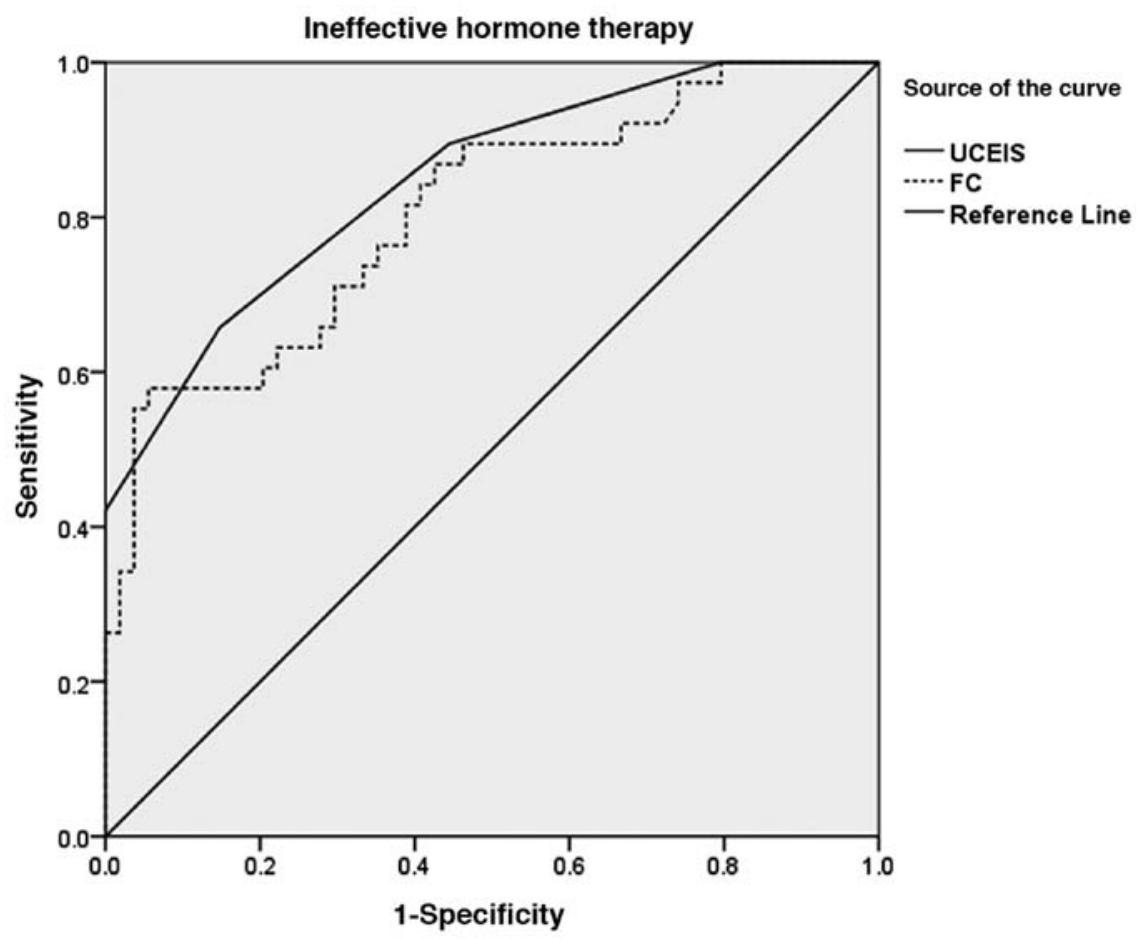

Figure 2. ROC curve of ineffective corticosteroid therapy. ROC, receiver operating characteristics.

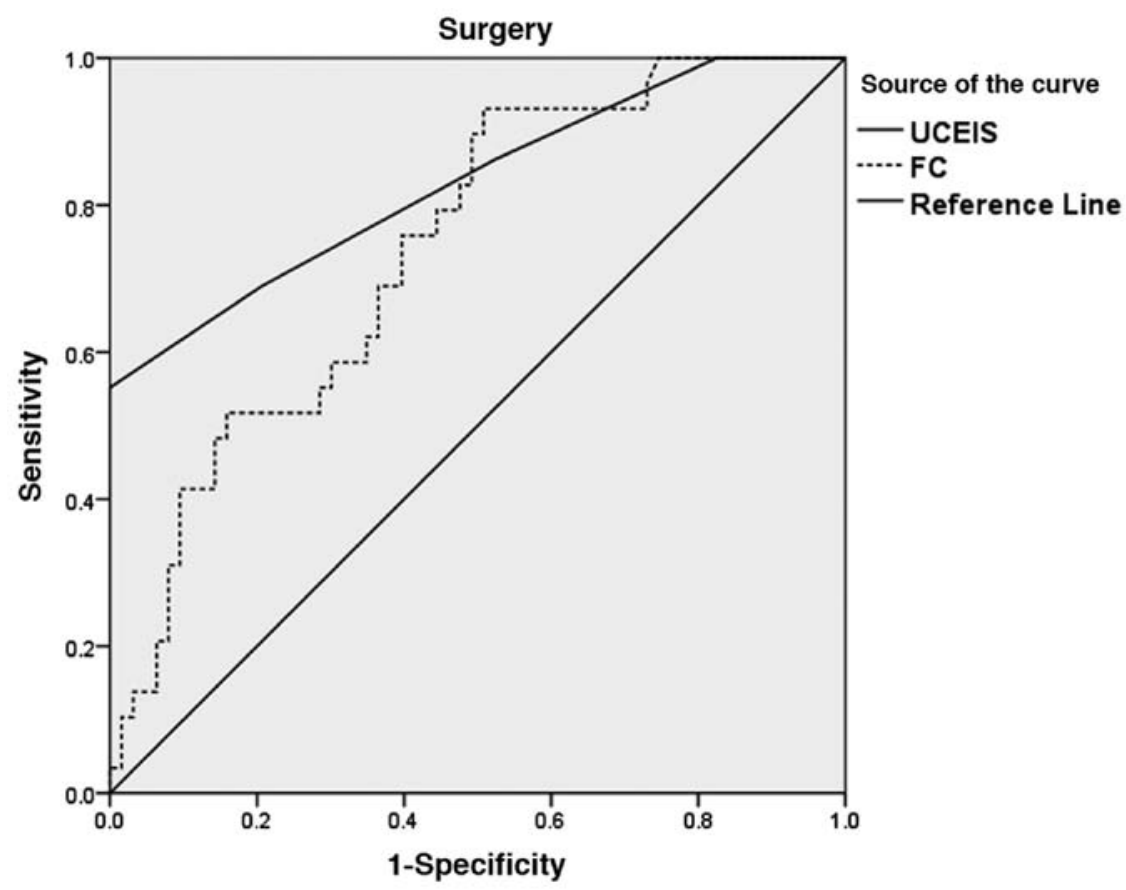

Figure 3. ROC curve of surgery. ROC, receiver operating characteristics.

\section{Discussion}

Approximately 30-40\% of ASC patients are unable to achieve clinical remission even with standard venous corticosteroid therapy (18). Selecting appropriate objective indicators to monitor changes in the patient's condition, together with timely, effective conversion of treatment strategies can reduce the risk of death in ASC patients and improve the success rate of salvage treatment or surgery $(3,19,20)$. For ASC, clinical symptoms cannot fully reflect the activity of the disease. Blood indicators such as CRP and erythrocyte sedimentation rate can only be used as indicators of systemic inflammatory response, but cannot directly reflect endoscopic intestinal mucosal damage.

Colonoscopy is still the gold standard for reflecting ASC activity. As an objective evaluation index for endoscopic intestinal mucosal injury, UCEIS score is receiving increasing attention. UCEIS is based on intestinal mucosal vascular network injury, erosive and ulcer status and bleeding, by 
assessing the most severe part of mucosal damage, maximizing the objectiveness of the results, eliminating $86-88 \%$ inter-observer heterogeneity, and significantly correlating with patients' clinical outcomes. Travis et al (10) found that, when the UCEIS score was 7-8, 13/14 of the symptoms in patients could not be relieved by intravenous corticosteroid therapy. However, colonoscopy, as an invasive examination, has a large burden on the patient. It is not well-accepted by the patients, and cannot continuously monitor the changes in patient's condition, often restricted in clinical practice. In patients with ASC, colonoscopy increases the risk of intestinal mucosal damage, and even results in toxic colitis and intestinal perforation.

FC detection is a convenient, non-invasive method for assessing intestinal mucosal damage. As a monitoring and evaluation tool, it can replace colonoscopy to some extent. FC was first isolated from neutrophils and monocytes by Fagerhol et al (15), and released into the intestinal lumen during the degerming process of inflammatory cells in the intestinal inflammation site. In patients with IBD, FC is an important intestinal inflammatory reactive protein, and FC plays a more important role in UC than Crohn's disease in determining disease activity. This study found that there was a statistically significant difference in FC concentrations between different UCEIS grades, and there was a correlation between the two. By analyzing CRP, ESR and $\mathrm{Hb}$, it was found that CRP and $\mathrm{Hb}$ can distinguish mild and moderate UCEIS, but lack sensitivity to endoscopic differentiation of moderate to severe mucosal lesions. After analyzing the correlation between UCEIS and CRP, ESR and $\mathrm{Hb}$, it was found that the correlation between UCEIS and the above three indicators was not good. The results indicated that CRP, as an inflammatory protein synthesized in the liver, lacks specificity for local inflammation in the intestine. As an indicator of acute and chronic infection, ESR is also less sensitive to ASC with different levels of activity. Patients with ASC are often accompanied by frequent bloody stools, and the progression of the disease may lead to decreased hemoglobin levels, but $\mathrm{Hb}$ does not distinguish endoscopic lesions.

The severity of ASC is directly related to the possibility of surgery. After 3 days of regular adequate steroid therapy, $85 \%$ of patients with hemorrhage more than 8 times/days or CRP greater than $45 \mathrm{mg} / \mathrm{l}$ will need surgery (21). Once a sufficient amount of steroid therapy for ASC patients for 305 days cannot achieve clinical remission, the treatment strategy should be switched immediately, and salvage treatment or surgery should be selected. There are a variety of clinical indicators for predicting surgery, in which the ones with good clinical operability and the comprehensive index composed of reliable and objective basis is applied in clinical practice, such as Oxford index, Swedish index and Ho index (21-23). The Oxford index and the Swedish index both consider CRP and the number of patients' bowel movements as an important part. The Ho index lists the expansion of the colon and hypoalbuminemia as an important part on the basis of the number of bowel movements. All three indicators have certain predictive value in clinical practice. For example, when the Swedish index is $>8$, the positive predictive value of surgery within 90 days is $69 \%$ (24). However, there are two main problems with the above clinical indicators. First, the classification is too simple, and the severity of inflammation in patients of the same level will be very different. Second, the indicators are mostly indirect, such as CRP, ALB level or the number of bowel movement, lack of direct attention to intestinal mucosal injury. Therefore, in the mid-1960s, Baron et al (25) introduced the degree of inflammation of the intestinal mucosa under colonoscopy into the Baron standard, which further increased the reliability of the standard.

This study confirmed that venous corticosteroid therapy had a higher failure rate ( $\mathrm{AUC}=0.805)$ when the FC concentration value was $>1327 \mu \mathrm{g} / \mathrm{g}$, and the patient has a higher degree of surgical potential (AUC $=0.740$ ) when the FC concentration was $>1681$, as a simple indicator of intestinal mucosal damage. For the assessment of the condition, FC is relatively convenient to detect, without damage to the patient, it is easily accepted, and can be repeatedly tested for real-time monitoring and guidance. Accurate assessment of the patient's condition and the likelihood of failure of the patient's corticosteroid therapy can help the clinician make timely clinical decisions. Insignificant corticosteroid therapy will reduce the success rate of salvage treatment and increase the risk of surgery. The delay of treatment time will also further worsen the patient's general condition, and increase the complications of surgery.

In conclusion, $\mathrm{FC}$ has a good correlation with UCEIS in ASC patients, and the correlation is better than CRP, ESR and $\mathrm{Hb} . \mathrm{Fc}$ is an ideal non-invasive procedure and is significantly associated with clinical outcomes in ASC patients. Dynamic monitoring of FC level in ASC patients can help clinicians accurately assess the likelihood of corticosteroid therapy and salvage treatment success, and change treatment strategy in a timely manner.

\section{Acknowledgements}

Not applicable.

\section{Funding}

No funding was received.

\section{Availability of data and materials}

The datasets used and/or analyzed during the current study are available from the corresponding author on reasonable request.

\section{Authors' contributions}

RMa and RMe conceived and designed the study, and drafted the manuscript. RMa, XZ, ZS and YL collected, analyzed and interpreted the experimental data. RMe revised the manuscript for important intellectual content. All authors read and approved the final manuscript.

\section{Ethics approval and consent to participate}

The study was approved by the Ethics Committee of Jining No. 1 People's Hospital (Jining, China). Signed informed consents were obtained from the patients and/or guardians. 


\section{Patient consent for publication}

Not applicable.

\section{Competing interests}

The authors declare that they have no competing interests.

\section{References}

1. Dinesen LC, Walsh AJ, Protic MN, Heap G, Cummings F, Warren BF, George B, Mortensen NJ and Travis SP: The pattern and outcome of acute severe colitis. J Crohn's Colitis 4: 431-437, 2010.

2. Edwards FC and Truelove SC: The course and prognosis of ulcerative colitis. Gut 4: 299-315, 1963.

3. Macken L and Blaker PA: Management of acute severe ulcerative colitis (NICE CG 166). Clin Med (Lond) 15: 473-476, 2015.

4. Park KT, Tsai R, Perez F, Cipriano LE, Bass D and Garber AM: Cost-effectiveness of early colectomy with ileal pouch-anal anastamosis versus standard medical therapy in severe ulcerative colitis. Ann Surg 256: 117-124, 2012.

5. Han W, Xu JM, Hu NZ, Mei Q and Liu MW: Early predictors of responses and clinical outcomes of corticosteroid treatment for severe ulcerative colitis. Scand J Gastroenterol 49: 424-433, 2014.

6. Travis S, Satsangi J and Lémann M: Predicting the need for colectomy in severe ulcerative colitis: A critical appraisal of clinical parameters and currently available biomarkers. Gut 60 : 3-9, 2011.

7. Walsh AJ, Ghosh A, Brain AO, Buchel O, Burger D, Thomas S, White L, Collins GS, Keshav S and Travis SP: Comparing disease activity indices in ulcerative colitis. J Crohn's Colitis 8: 318-325, 2014

8. D'Haens G, Sandborn WJ, Feagan BG, Geboes K, Hanauer SB, Irvine EJ, Lémann M, Marteau P, Rutgeerts P, Schölmerich J, et al: A review of activity indices and efficacy end points for clinical trials of medical therapy in adults with ulcerative colitis. Gastroenterology 132: 763-786, 2007.

9. Travis SPL, Schnell D, Krzeski P, Abreu MT, Altman DG, Colombel JF, Feagan BG, Hanauer SB, Lémann M, Lichtenstein GR, et al: Developing an instrument to assess the endoscopic severity of ulcerative colitis: The Ulcerative Colitis Endoscopic Index of Severity (UCEIS). Gut 61: 535-542, 2012.

10. Travis S, Corte $\mathrm{C}$ and Keshav S: Does disease extent matter when scoring the UCEIS? J Crohn's Colitis 9: 694, 2015.

11. Travis SPL, Schnell D, Feagan BG, Abreu MT, Altman DG, Hanauer SB, Krzeski P, Lichtenstein GR, Marteau PR, Mary JY, et al: The impact of clinical information on the assessment of endoscopic activity: Characteristics of the ulcerative colitis endoscopic index of severity. J Crohn's Colitis 9: 607-616, 2015.
12. Fefferman DS and Farrell RJ: Endoscopy in inflammatory bowel disease: Indications, surveillance, and use in clinical practice. Clin Gastroenterol Hepatol 3: 11-24, 2005.

13. Røseth AG, Aadland E, Jahnsen J and Raknerud N: Assessment of disease activity in ulcerative colitis by faecal calprotectin, a novel granulocyte marker protein. Digestion 58: 176-180, 1997.

14. Lobatón T, Rodríguez-Moranta F,Lopez A, Sánchez E, RodríguezAlonso L and Guardiola J: A new rapid quantitative test for fecal calprotectin predicts endoscopic activity in ulcerative colitis. Inflamm Bowel Dis 19: 1034-1042, 2013.

15. Fagerhol MK: Calprotectin, a faecal marker of organic gastrointestinal abnormality. Lancet 356: 1783-1784, 2000.

16. Goenka MK, Nag S, Kumar A and Pai CG: Diagnosis of acute severe colitis. Trop Gastroenterol 35 (Suppl 1): S1-S8, 2014.

17. Chinese Medical Association Digestive Diseases Branch Inflammatory Bowel Disease Cooperative Group: Consensus on the diagnosis and treatment of inflammatory bowel disease in China. Chin J Integr Med 47: 73-79, 2008.

18. Bewtra M, Newcomb CW, Wu Q, Chen L, Xie F, Roy JA, Aarons CB, Osterman MT, Forde KA, Curtis JR, et al: Mortality associated with medical therapy versus elective colectomy in ulcerative colitis: A cohort study. Ann Intern Med 163: 262-270, 2015.

19. Andersson P, Söderholm JD and Derholm JD: Surgery in ulcerative colitis: Indication and timing. Dig Dis 27: 335-340, 2009.

20. Gulliford SR and Limdi JK: Acute severe ulcerative colitis: Timing is everything. Postgrad Med J 87: 215-222, 2011.

21. Travis SP, Farrant JM, Ricketts C, Nolan DJ, Mortensen NM, Kettlewell MG and Jewell DP: Predicting outcome in severe ulcerative colitis. Gut 38: 905-910, 1996.

22. Lindgren SC, Flood LM, Kilander AF, Löfberg R, Persson TB and Sjödahl RI: Early predictors of glucocorticosteroid treatment failure in severe and moderately severe attacks of ulcerative colitis. Eur J Gastroenterol Hepatol 10: 831-835, 1998.

23. Ho GT, Mowat C, Goddard CJ, Fennell JM, Shah NB, Prescott RJ and Satsangi J: Predicting the outcome of severe ulcerative colitis: Development of a novel risk score to aid early selection of patients for second-line medical therapy or surgery. Aliment Pharmacol Ther 19: 1079-1087, 2004.

24. Järnerot G, Hertervig E, Friis-Liby I, Blomquist L, Karlén P, Grännö C, Vilien M, Ström M, Danielsson A, Verbaan H, et al: Infliximab as rescue therapy in severe to moderately severe ulcerative colitis: A randomized, placebo-controlled study. Gastroenterology 128: 1805-1811, 2005.

25. Baron JH, Connell AM and Lennard-Jones JE: Variation between observers in describing mucosal appearances in proctocolitis. BMJ 1: 89-92, 1964

This work is licensed under a Creative Commons Attribution-NonCommercial-NoDerivatives 4.0 International (CC BY-NC-ND 4.0) License. 